\title{
Optimizing potassium ferrate for textile wastewater treatment by RSM
}

\author{
Maryam Moradnia ${ }^{1}$, Masoud Panahifard ${ }^{1}$, Kavoos Dindarlo ${ }^{2}$, Hamzeh Ali Jamali ${ }^{3^{*}}$ \\ ${ }^{1}$ MSc Student in Environmental Health Engineering, Health Faculty, Qazvin University of Medical Science, Qazvin, Iran \\ ${ }^{2}$ Assistant Professor of Environmental Health Engineering, Health Faculty, Hormozgan University of Medical Science, \\ Hormozgan, Iran \\ ${ }^{3}$ Assistant Professor of Environmental Health Engineering, Health Faculty, Qazvin University of Medical Science, Qazvin, Iran
}

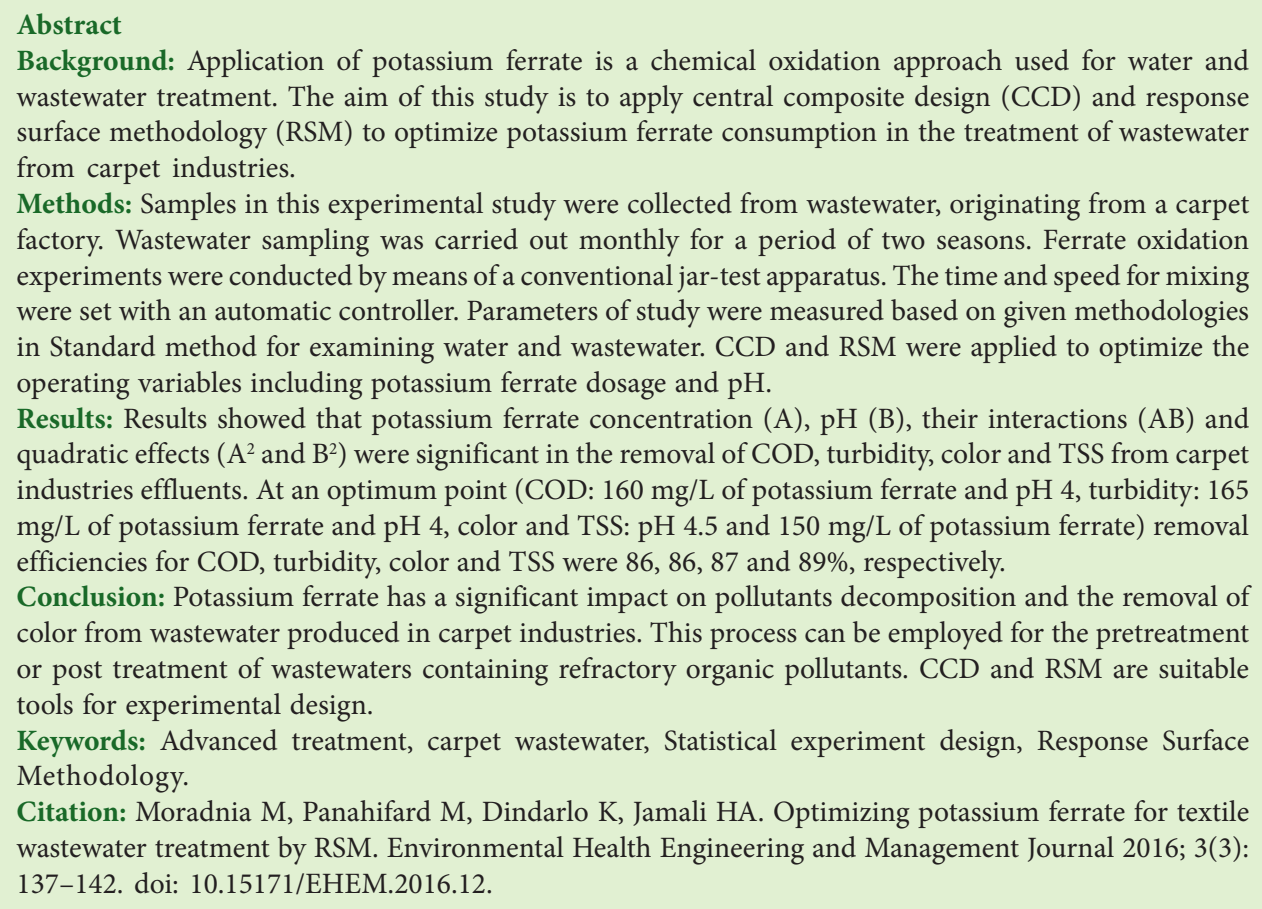

Keywords: Advanced treatment, carpet wastewater, Statistical experiment design, Response Surface Methodology.

Citation: Moradnia M, Panahifard M, Dindarlo K, Jamali HA. Optimizing potassium ferrate for textile wastewater treatment by RSM. Environmental Health Engineering and Management Journal 2016; 3(3): 137-142. doi: 10.15171/EHEM.2016.12.

Article History:

Received: 5 June 2016

Accepted: 11 July 2016

ePublished: 1 August 2016

\section{Introduction}

A large amount of wastewater produced in textile industries emerges from color containing units with a wide range of contaminants that must be treated before being discharged into the environment. Wastewater originating from color-containing effluents embodies a high COD, large fluctuations, high $\mathrm{pH}$ and temperature (1). Moreover, in many cases, these effluents are toxic and lead to ecosystem damage by producing some hazardous byproducts. Application of potassium ferrate as an advanced approach is appropriate for the treatment of such types of wastewater $(2,3)$.

Potassium ferrate $\left(\mathrm{K}_{2} \mathrm{FeO}_{4}\right)$ is a ferrous salt (iron salt) containing an uncommon ion with oxidation valence +6 . The ion $\left(\mathrm{FeO}_{4}\right)^{-2}$ is a strong oxidant and its oxidizing potential in acidic and alkaline conditions is 2.2 and $0.72 \mathrm{~V}$ respectively. As potassium ferrate is reduced to $\mathrm{Fe}^{3+}$ ions or ferric hydroxide during oxidation process, it is capable of conducting coagulation. As a result, potassium ferrate has two functions in water and wastewater treatment: oxidation and coagulation. Hence, it is recommended for the removal of environmental contaminants. This chemical compound is a green chemical $(4,5)$ and its reaction in aquatic environment is shown in Eq. (1).

$$
\mathrm{FeO}_{4}^{2-}+8 \mathrm{H}^{+}+3 e^{-} \rightarrow \mathrm{Fe}^{3+}+4 \mathrm{H}_{2} \mathrm{O}
$$

Ferrate (VI) has been successfully utilized in water and wastewater treatment (6). Currently, some researches has been carried out regarding the removal of pharmaceutical contaminants and micro pollutants utilizing ferrate (VI) and the results showed the effective impact of this com- 
pound in decomposition of such contaminants in aquatic environment.

The limitations of classical methods include high time consumption due to numerous experiments and high cost of consumables that can be omitted by statistical experimental designs. Furthermore, in this approach, it is impossible to examine the interactions among variables (7). Response surface methodology (RSM) is an appropriate method that can resolve these limitations. In this study, RSM was employed to optimize variables influencing the elimination of chemical oxygen demand (COD), color, turbidity and TSS from wastewater. RSM was derived from statistical and mathematical technique. It can be used to study the effect of several factors at three or five level as well as their influence on each other (8). In this study, central composite design (CCD) was utilized for experimental design. It is an effective design that does not need a greater number of experimental runs (9). Moreover, experimental designs such as CCD model provides valuable data on direct, pair wise interaction, and curvilinear variable effects (7). This study uses CCD and RSM to optimize potassium ferrate consumption in the treatment of wastewater from textile industry.

\section{Methods}

Experimental setup and procedure

Samples were collected from a carpet factory's effluents. The colors utilized in this industry were of azo and anthraquinone types. Sampling was carried out monthly and during summer and fall. The samples were transferred to the laboratory of Qazvin University of Medical Sciences in less than 48 hours at $4^{\circ} \mathrm{C}$. The conductivity and $\mathrm{pH}$ of the samples were measured with a Multi WTW 340i instrument (Germany). Total organic carbon (TOC) content of the samples was determined employing an ANATEC TOC analyzer (model ANATEC II Australia). Total solids (TS), total suspended solids (TSS), total volatile solids (TVS), total dissolved solids (TDS), turbidity, alkalinity, acidity and COD were determined based on standard methods for the examination of water and wastewater (10).

Ferrate oxidation experiments were conducted by means of a conventional jar-test (zag-shimi, Iran) apparatus with impellers equipped with six of $1.5 \mathrm{~cm} \times 4.5 \mathrm{~cm}$ rectangular blades. The time and speed for mixing were set with an automatic controller. Jar testing steps include rapid mix with the mixing speed of $200 \mathrm{rpm}$ for one minute, slow mix with the mixing speed of $40 \mathrm{rpm}$ for 20 minutes and settlement for 60 minutes. Potassium ferrate (97\%) was provided by Sigma-Aldrich Corporation (USA). Other chemicals were of analytical grade and purchased from Merck (Germany). In order to adjust $\mathrm{pH}, 0.1 \mathrm{M}$ sulfuric acid and $0.05 \mathrm{~L}$ of sodium hydroxide solution was used. A total of 30 preliminary experiments were carried out to determine $\mathrm{pH}$ range and the amount of ferrate needed, based on literature reviews (3). The active ferrate solution $(1 \mathrm{~g} / \mathrm{L})$ was prepared by adding the solid form of $\mathrm{K}_{2} \mathrm{FeO}_{4}$ to $0.005 \mathrm{M} \mathrm{Na}_{2} \mathrm{HPO}_{4}$ solution and $0.001 \mathrm{M}$ borate buffer at $\mathrm{pH} 9$.
Experimental design and model development In this study, determination of optimum conditions $(\mathrm{pH}$ and potassium ferrate consumption) for the removal of COD, color, turbidity and TSS was carried out employing CCD/RSM procedures. Design Expert software (Stat-Ease Inc., Minneapolis, USA) was applied for designing, statistical modeling and optimization. Model statistics computed were F-value, Lack of fit, coefficient of determination $\left(\mathrm{R}^{2}\right)$, and coefficient of variation $(\mathrm{CV})$. Generally, a good model must be significant based on $P$ value and $F$ value as opposed to the lack of fit (insignificant).

The independent variables were concentration of potassium ferrate $(\mathrm{mg} / \mathrm{L})$ and $\mathrm{pH}$ denoted by $\mathrm{A}$ and $\mathrm{B}$ respectively. Furthermore, the removal efficiencies of COD, turbidity, color and TSS were considered as response variables that are denoted by $\mathrm{Y}_{1}, \mathrm{Y}_{2}, \mathrm{Y}_{3}$ and $\mathrm{Y}_{4}$, respectively. Performance of the procedure was evaluated by assessing the efficiency of COD, turbidity, color and TSS removals. The variables were coded according to Eq. (2):

$\mathrm{x}_{\mathrm{i}}=\frac{\mathrm{x}_{\mathrm{i}}-\mathrm{x}_{0}}{\Delta \mathrm{x}} \mathrm{i}=1,2,3, \ldots \mathrm{k}$

Where $x_{i}$ is the coded value of the independent variable, $x_{0}$ is the value of $x_{i}$ at the center point and $\Delta x$ is the difference of variable values. The maximum, central and minimum values $(+1,0,-1)$ of each variable was specified based on CCD. In this study, CCD included $2^{\mathrm{k}}$ fractional factorial points $(\mathrm{k}=2), 2 \mathrm{k}$ axial points and 5 center points. Thus, 13 experiments including 4 factorial points, and 4 axial points were carried out. In order to evaluate the pure error, 5 additional experiments were carried out at the center point. Following the analysis of experimental data, optimal conditions were graphically determined. Determination of optimum conditions for several parameters was carried out by overlaying of plots called graphical optimization. Graphical optimization reveals the area of feasible response values in the factor space and the regions that do fit the optimization criteria would be shaded $(7,8)$.

To confirm the results obtained from experimental data, two additional experiments were carried out in optimum conditions and the results were compared. System behavior was described by Eq. (3) which is an experimental quadratic polynomial model.

$$
Y=\beta 0+\sum_{i=1}^{k} \beta i . x i+\sum_{i=1}^{k} \beta i i . x i^{2}+\sum_{i \leq j}^{k} \sum_{j}^{k} \beta i j . x i . x j+\ldots+\mathrm{e}
$$

Where $Y, i, j, \beta$, e and $k$ represent the response variable, linear constant, quadratic constant, regression constant, random error as well as the number of parameters, respectively.

The minimum and maximum range of variables was investigated along with the full experimental plan, with respect to their values in actual and coded form as listed in Table 1 .

\section{Results}

The results of qualitative analysis of the wastewater are shown in Table 2. 
Table 1. Independent variables and limit level for response surface study

\begin{tabular}{|c|c|c|c|c|c|c|c|}
\hline \multirow{2}{*}{ Variables } & \multirow{2}{*}{ Unit } & \multirow{2}{*}{ Coded symbols } & \multicolumn{5}{|c|}{ Levels } \\
\hline & & & -1 & -0.5 & 0 & +0.5 & +1 \\
\hline Doses of potassium ferrate & $\mathrm{mg} / \mathrm{L}$ & A & 50 & 75 & 150 & 175 & 200 \\
\hline $\mathrm{pH}$ & - & B & 3 & 3.75 & 4.5 & 5.25 & 6 \\
\hline
\end{tabular}

Based on the 13 experimental results, the CCD for the experimental variables is shown in Table 3 .

According to the obtained results, the highest removal efficiencies for COD, turbidity, color and TSS were $90 \%$, $87 \%, 89.6 \%$ and $91 \%$, respectively.

The results obtained from analysis of variance (ANOVA) with regards to the removal of COD, turbidity, color and TSS utilizing potassium ferrate are shown in Table 4. As shown in Table 4, all the terms in the statistical quadratic model were significant $(P \leq 0.0001)$. Lack of fit test for COD, turbidity, color and TSS removal $(P=0.4560$, $0.7661,0.4735,0.7152$, respectively) were not significant. The variables $\mathrm{R}^{2}$ (coefficient of determination), A.R $\mathrm{R}^{2}$ (adjusted $\mathrm{R}^{2}$ ), A.P (adequate precision) and C.V (coefficient of variance) are shown in Table $4 . \mathrm{R}^{2}$ and A. $\mathrm{R}^{2}$ were found to be $0.96,0.99,0.99$ and $0.98,0.94,0.97,0.98$ and 0.97 for the removal of COD, turbidity, color and TSS respectively. The obtained values of AP and C.V for the mentioned parameter were $19.21,30.13,30.32$ and $22.3,3.4,2.05,3.4$ and 3.83 respectively.

The ANOVA results for each response (Table 4) indicated that the linear of two independent variables (A and B),

Table 2. Characteristics of raw wastewater from the carpet factory

\begin{tabular}{lc}
\hline Parameters & Mean \pm SD \\
\hline $\mathrm{pH}$ & $6.54 \pm 1.2$ \\
$\mathrm{EC}(\mu \mathrm{S} / \mathrm{Cm})$ & $950 \pm 20$ \\
$\mathrm{TOC}(\mathrm{mg} / \mathrm{L})$ & $700 \pm 30$ \\
$\mathrm{COD}(\mathrm{mg} / \mathrm{L})$ & $1600 \pm 50$ \\
$\mathrm{TSS}(\mathrm{mg} / \mathrm{L})$ & $280 \pm 20$ \\
$\mathrm{TDS}(\mathrm{mg} / \mathrm{L})$ & $900 \pm 30$ \\
TVS (mg/L) & $850 \pm 40$ \\
\hline Turbidity (NTU) & $554 \pm 15$ \\
\hline Alkalinity (mg/L as CaCo $)$ & $180 \pm 30$ \\
\hline Acidity (mg/L as CaCo3) & $40 \pm 3.5$ \\
\hline
\end{tabular}

Table 3. CCD for the experimental variables

\begin{tabular}{lccccccc}
\hline \multirow{2}{*}{ No. } & \multirow{2}{*}{ Run } & \multirow{2}{*}{$\mathbf{p H}$} & $\begin{array}{c}\text { Potassium } \\
\text { ferrate }(\mathrm{mg} / \mathrm{L})\end{array}$ & \multicolumn{4}{c}{ Removal efficiency (\%) } \\
\cline { 5 - 8 } & & & COD & Turbidity & Color & TSS \\
\hline 1 & 4 & 6 & 200 & 75 & 75 & 55 & 50.4 \\
\hline 2 & 10 & 4.5 & 150 & 85 & 84 & 83.4 & 90.1 \\
\hline 3 & 1 & 3 & 50 & 75 & 71 & 49 & 44 \\
\hline 4 & 11 & 4.5 & 150 & 90 & 87 & 85.7 & 90 \\
\hline 5 & 12 & 4.5 & 150 & 87 & 87 & 88 & 83 \\
\hline 6 & 13 & 4.5 & 150 & 83 & 83 & 89.6 & 91 \\
\hline 7 & 2 & 6 & 50 & 50 & 52 & 35 & 45 \\
\hline 8 & 8 & 4.5 & 175 & 83.9 & 85 & 85.5 & 85.2 \\
\hline 9 & 9 & 4.5 & 150 & 85 & 84 & 88.4 & 87.4 \\
\hline 10 & 3 & 3 & 200 & 65 & 67.5 & 54.3 & 46.3 \\
\hline 11 & 5 & 3.75 & 150 & 80 & 82 & 78.5 & 86 \\
\hline 12 & 6 & 5.25 & 150 & 82 & 82 & 80 & 77.8 \\
\hline 13 & 7 & 4.5 & 75 & 81.5 & 80 & 77.8 & 78 \\
\hline
\end{tabular}

Table 4. ANOVA results for the removal of COD, turbidity, color and TSS using potassium ferrate

\begin{tabular}{|c|c|c|c|c|c|}
\hline Source & $\begin{array}{l}\text { Sum of } \\
\text { squares }\end{array}$ & df & $\begin{array}{c}\text { Mean } \\
\text { squares }\end{array}$ & F-value & $P$ value \\
\hline \multicolumn{6}{|c|}{ COD removal (\%) } \\
\hline Model & 1330.18 & 5 & 266.04 & 36.91 & $<0.0001$ \\
\hline$A$ & 43.56 & 1 & 43.56 & 6.04 & 0.0436 \\
\hline B & 58.32 & 1 & 58.32 & 8.09 & 0.0249 \\
\hline$A B$ & 306.25 & 1 & 306.25 & 42.49 & 0.0003 \\
\hline$A^{2}$ & 41.08 & 1 & 41.08 & 5.7 & 0.0483 \\
\hline$B^{2}$ & 9.31 & 1 & 9.31 & 1.29 & 0.2931 \\
\hline Residual & 50.45 & 7 & 7.21 & & \\
\hline Lack of fit & 22.45 & 3 & 7.48 & 1.07 & 0.4560 \\
\hline Pure error & 28 & 4 & 7 & & \\
\hline \multicolumn{6}{|c|}{ Turbidity removal (\%) } \\
\hline Model & 1167.81 & 5 & 233.56 & 90.24 & $<0.0001$ \\
\hline A & 29.39 & 1 & 29.39 & 11.35 & 0.0119 \\
\hline B & 107.56 & 1 & 107.56 & 41.56 & 0.0004 \\
\hline$A B$ & 175.56 & 1 & 175.56 & 67.83 & $<0.0001$ \\
\hline$A^{2}$ & 25.57 & 1 & 25.57 & 9.88 & 0.0163 \\
\hline$B^{2}$ & 16.55 & 1 & 16.55 & 6.4 & 0.0393 \\
\hline Residual & 18.21 & 7 & 2.59 & & \\
\hline Lack of fit & 4.12 & 3 & 1.37 & 0.39 & 0.7661 \\
\hline Pure error & 14 & 4 & 3.5 & & \\
\hline \multicolumn{6}{|c|}{ Color removal (\%) } \\
\hline Model & 3916.35 & 5 & 783.27 & 127.7 & $<0.0001$ \\
\hline A & 35 & 1 & 35 & 5.71 & 0.0483 \\
\hline B & 188.83 & 1 & 188.83 & 30.79 & 0.0009 \\
\hline$A B$ & 54.02 & 1 & 54.02 & 8.81 & $<0.0209$ \\
\hline$A^{2}$ & 138.64 & 1 & 138.64 & 22.6 & 0.0021 \\
\hline$B^{2}$ & 49.47 & 1 & 49.47 & 8.07 & 0.0250 \\
\hline Residual & 42.93 & 7 & 6.13 & & \\
\hline Lack of fit & 18.57 & 3 & 6.19 & 1.02 & 0.4735 \\
\hline Pure error & 24.37 & 4 & 6.09 & & \\
\hline \multicolumn{6}{|c|}{ TSS removal (\%) } \\
\hline Model & 3717.15 & 5 & 743.43 & 90.55 & $<0.0001$ \\
\hline A & 54.43 & 1 & 54.43 & 6.63 & 0.0368 \\
\hline B & 179.24 & 1 & 179.24 & 21.83 & 0.0023 \\
\hline$A B$ & 49 & 1 & 49 & 5.97 & $<0.0446$ \\
\hline$A^{2}$ & 70.6 & 1 & 70.6 & 8.6 & 0.0219 \\
\hline$B^{2}$ & 97.69 & 1 & 97.69 & 11.9 & 0.0107 \\
\hline Residual & 57.47 & 7 & 8.21 & & \\
\hline Lack of fit & 15.15 & 3 & 5.05 & 0.48 & 0.7152 \\
\hline Pure error & 42.32 & 4 & 10.58 & & \\
\hline \multicolumn{6}{|c|}{ Other statistical parameters } \\
\hline & $\mathbf{R}^{2}$ & Adj. $R^{2}$ & Mean \pm SD & AP & CV \\
\hline COD & 0.96 & 0.94 & $78.65 \pm 2.68$ & 19.21 & 3.4 \\
\hline Turbidity & 0.99 & 0.97 & $78.4 \pm 1.61$ & 30.13 & 2.05 \\
\hline Color & 0.99 & 0.98 & $73.1 \pm 2.48$ & 30.32 & 3.4 \\
\hline TSS & 0.98 & 0.97 & $74.78 \pm 2,87$ & 22.3 & 3,83 \\
\hline
\end{tabular}


quadratic effects $\left(\mathrm{A}^{2}\right.$ and $\left.\mathrm{B}^{2}\right)$ and their interactions $(\mathrm{AB})$ were significant $(P \leq 0.0001)$ in the removal of COD, turbidity, color and TSS. As presented in Table 4, the Fisher coefficient (F-value) for the removal of COD, turbidity, color and TSS were significant.

The final quadratic equations for the removal of the study parameters were obtained as shown in Eq. (4) to (7). COD removal $(\%) \mathrm{Y}_{1}=85.2-3.11 \mathrm{~A}+3.6 \mathrm{~B}+8.75 \mathrm{AB}-$ 12.98A2-6.18B2

Turbidity removal $(\%) \mathrm{Y}_{2}=84.82-2.56 \mathrm{~A}+4.9 \mathrm{~B}+6.62 \mathrm{AB}$ $-10.24 \mathrm{~A} 2-8.24 \mathrm{~B} 2$

Color removal $(\%) \mathrm{Y}_{3}=86.27-2.79 \mathrm{~A}+6.48 \mathrm{~B}+3.67 \mathrm{AB}$ $-23.84 \mathrm{~A} 2+14.24 \mathrm{~B} 2$

TSS removal (\%) $\mathrm{Y}_{4}=87.6-3.48 \mathrm{~A}+6.31 \mathrm{~B} 3.5-\mathrm{AB}$ -17.01A2- $20.01 \mathrm{~B} 2$

The model equations were employed to generate $3 \mathrm{D}$ contour plots. The 3D contour plots for the effective factors in eliminating COD, turbidity, color and TSS are plotted in Figure 1. As shown in the plots, all responses have an optimum removal point. With respect to Figure $1 \mathrm{~A}$ and $1 \mathrm{~B}$, the optimum $\mathrm{pH}$ for the removal of COD and turbidity was 4 , while it was 4.5 for color and TSS removal (Figure $1 \mathrm{C}$ and $1 \mathrm{D})$. Also, the optimum dose of potassium ferrate for the removal of COD and turbidity were obtained as 160 and $165 \mathrm{mg} / \mathrm{L}$, respectively, while it was $150 \mathrm{mg} / \mathrm{L}$ for color and TSS removal. In this condition, removal efficiencies for COD, turbidity, color and TSS were $86 \%, 86 \%$, $87 \%$ and $89 \%$, respectively.

By overlaying four 3D plots, the optimum removal efficiencies for COD, turbidity, color and TSS were obtained as $84 \%, 85 \%, 85 \%$ and $87 \%$, respectively. In this condition, the dose of potassium ferrate and $\mathrm{pH}$ value was obtained as $160 \mathrm{mg} / \mathrm{L}$ and 4.3 respectively after overlaying four 3D plots (Figure 2).

Based on the results obtained from the final quadratic model, to confirm the reliability of the model, two additional laboratory experiments were carried out utilizing the optimum conditions suggested by the Design-Expert software as shown in Table 5.

The optimum conditions were obtained at $\mathrm{pH} 4.3$ and $160 \mathrm{mg} / \mathrm{L}$ potassium ferrate concentration. At optimum conditions, COD, turbidity, color and TSS efficiency were obtained $84.5,85,85.3$ and $88.3 \%$ respectively.

\section{Discussion}

The quality of quadratic polynomial model fit was expressed by $\mathrm{R}^{2}$ and Adj. $\mathrm{R}^{2}$. $\mathrm{R}^{2}$ should be close to 1 , as this

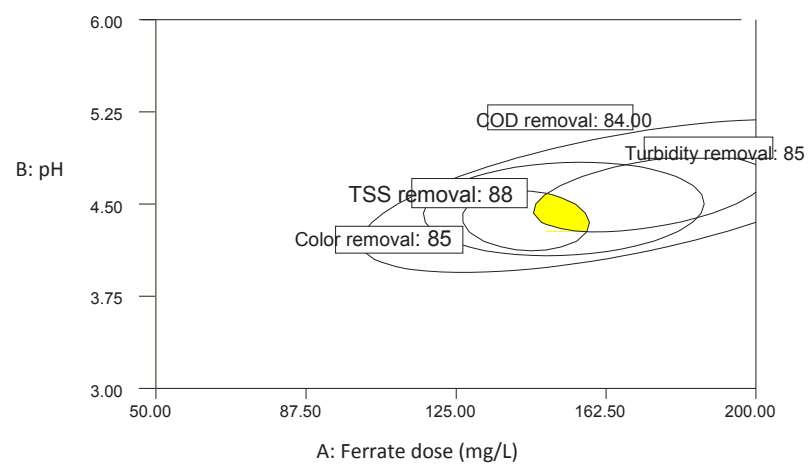

Figure 2. The overlaying plots for the removal of COD, turbidity, color and TSS

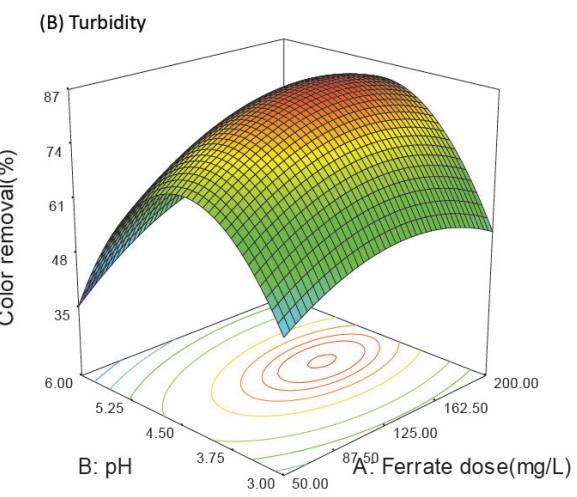

(D) TSS

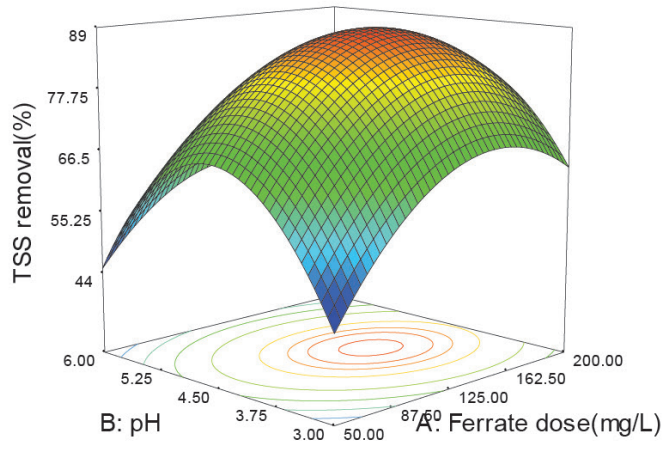

Figure 1. The 3D contour plots for the removal of COD, turbidity, color and TSS by potassium ferrate. 
Table 5. Verification of experimental results at optimum conditions

\begin{tabular}{lccc}
\hline $\begin{array}{l}\text { Optimum condition (pH } \mathbf{4 . 3} \text { and } \\
\text { ferrate dose } \mathbf{1 6 0} \mathbf{~ m g / L )}\end{array}$ & $\begin{array}{c}\text { COD removal efficiency } \\
\text { (\%) }\end{array}$ & $\begin{array}{c}\text { Turbidity removal } \\
\text { efficiency (\%) }\end{array}$ & $\begin{array}{c}\text { Color removal efficiency } \\
\text { (\%) }\end{array}$ \\
\hline Experimental results & $83 \%$ & $84.1 \%$ & $84.5 \%$ \\
Model response & $84.5 \%$ & $85 \%$ & $85.3 \%$ \\
Error & 1.5 & 0.9 & 0.7 \\
Standard deviation & 0.7 & 0.43 & 0.3 \\
\hline
\end{tabular}

would show better correlation between the predicted and experimental values. A high $\mathrm{R}^{2}$ coefficient ensures a satisfactory adjustment of the quadratic model to the experimental data. As a result, an optimal agreement with the adjusted $\mathrm{R}^{2}$ is important $(8,9)$. In this research, in all cases, $\mathrm{R}^{2}$ coefficient was high. The high values of $\mathrm{R}^{2}$ suggest the high agreement of the obtained experimental data, with the data evaluated by the model. So, it can be said that the quadratic model has a good fitness for the data. Adequate precision is a measure of the range in predicted response relative to its associated error, in other words, a signal-tonoise ratio. Its desired value is 4 or more $(11,12)$. In this study, AP values for the removal of COD, turbidity, color and TSS were greater than 4 indicating the existence of adequate signal and the high capability of this model in predicting the results. Coefficient of variance (CV) estimates the ratio of the standard error to the mean value of the observed responses (as a percentage) and also describes the reproducibility of models. Normally, we can consider a model to be reproducible when its $\mathrm{CV}$ is not greater than $10 \%$ (9). CV was within the acceptable range of $10 \%$ which proves the reproducibility of the model and high precision in the results. All of these terms indicated a good fitting when there is high correlation between the observed and predicted values. The lack of fit (LOF) F-test describes the variation of data around the fitted model. If the model does not fit the data well, the lack of fit test will be significant (8). Lack of fit test for COD, turbidity, color and TSS responses were not significant, thus it shows a good fitting of the data to the model.

The response surface plots were approximately symmetrical in shape with circular contours. All response plots showed clear peaks, indicating that optimal conditions for the maximum responses depend on the dose potassium ferrate and $\mathrm{pH}$ in the design space. Initial concentration of ferrate and initial $\mathrm{pH}$ value has a significant influence in the oxidative ability of the ferrate ion. With respect to Figure 1, the interaction effects of ferrate dose and $\mathrm{pH}$ on responses, demonstrate concentrically closed curves. The centers represent the optimum conditions, indicating that experimental design has been well carried out. Furthermore, the experimental results which were obtained from the optimum conditions, showed the precision of the resulting data and models.

Previous studies have reported that potassium ferrate can also eliminate a range of metals (e.g., $\mathrm{Fe}^{2+}, \mathrm{Fe}^{3+}, \mathrm{Mn}^{2+}$, and $\mathrm{Cu}^{2+}$ ) and toxic heavy metals (e.g., $\mathrm{Pb}^{2+}, \mathrm{Cd}^{2+}, \mathrm{Cr}^{3+}$, and $\mathrm{Hg}^{2+}$ ) to a low level at a dose range of $10-100 \mathrm{mg} / \mathrm{L}$ as $\mathrm{K}_{2} \mathrm{FeO}_{4}(13,14)$.

The results of a study carried out on the application of
$70 \mathrm{mg} / \mathrm{L}$ potassium ferrate for the treatment of colorcontained textile wastewater, indicated that high removal efficiencies of COD, color and turbidity were $91 \%, 50 \%$ and $93 \%$, respectively. Except the color removal efficiency, other variables were consistent with current study (15). This can be due to different characteristics of textile wastewater.

Some researchers employed encapsulated potassium ferrate (VI) for the removal of DNBP (dinitro butylphenol). The optimal conditions regarding the degradation of DNBP were $\mathrm{pH} 6.5$ and encapsulated concentration of 1.2 $\mathrm{g} / \mathrm{L}$. They also reported that encapsulated potassium ferrate (VI) was very effective in COD reduction as well as the decolorization of real wastewater from the manufacturing of DNBP. In addition, they stated that the removal of DNBP increased with encapsulated Fe (VI) concentration. The DNBP removal increased with corresponding efficiency from $68 \%$ to $93 \%$ when the encapsulated $\mathrm{Fe}$ (VI) dosage increases from 0.4 to $1.2 \mathrm{~g} / \mathrm{L}$ (16). High consumption of ferrate for the degradation of DNBP may be as a result of complex structure of this compound.

The results of a study showed the highest removal efficiencies for Ibuprofen and Ciprofloxacin by potassium ferrate in $\mathrm{pH} 4$ and 5-6, respectively (17). Moreover, another research reported complete removal of flurbiprofen from aqueous solutions by ferrate in $\mathrm{pH} 4$ (18), which were in agreement with our study.

The results of a research carried out on the removal of bisphenol compounds by ferrate (VI) indicated that when $\mathrm{pH}$ increases from 3 to 5 , bisphenol removal efficiency by ferrate (VI) would increase from $85.1 \%$ to $95.2 \%$ (19). Our results were in line with those of the mentioned study.

A study carried out in relation to the removal of turbidity and COD in the batch reactor with ferrate dose of 15 $\mathrm{mg} / \mathrm{L}$ for secondary wastewater treatment, showed a significant improvement with respect to the removal of suspended solids (70.8\%) and turbidity (78\%) (20). The low consumption of potassium ferrate when compared to the findings of our study may be as a result of low concentration of organic matters in secondary effluent.

A report obtained on the comparative performance of potassium ferrate (VI) and ferric sulphate for the removal of COD, color and turbidity in sewage treatment, showed that potassium ferrate (VI) could reduce COD and organic contaminants in comparison with ferric sulphate for the same doses utilized. Furthermore, the volume of sludge produced by potassium ferrate (VI) was much less than ferric sulphate, which ought to make subsequent treatment of sludge easier. 


\section{Conclusion}

Potassium ferrate is an effective compound for the treatment of wastewater from carpet factories. However, the limitations of the ferrate application are related to the instability of its solutions along with the complicated preparation and storage of this compound.

CCD of RSM can be utilized to determine the significant variables and optimum condition for textile wastewater treatment with respect to COD, TSS, turbidity, and color removal. Potassium ferrate concentration (A), $\mathrm{pH}(\mathrm{B})$, their interactions $(\mathrm{AB})$ and quadratic effects $\left(\mathrm{A}^{2}\right.$ and $\left.\mathrm{B}^{2}\right)$ were significant in the removal of COD, turbidity, color and TSS from carpet industries effluents. The statistical approach has been confirmed to be a powerful tool in studying textile wastewater treatment utilizing potassium ferrate.

\section{Acknowledgments}

The authors would like to appreciate the technical support provided by Qazvin University of Medical Sciences.

\section{Ethical issues}

The authors certify that all data collected during the study is as stated in this manuscript, and no data from the study has been or will be published separately elsewhere.

\section{Competing interests}

The authors declare that they have no competing interests.

\section{Authors' contributions}

All authors contributed equally to data collection, and article approval.

\section{References}

1. Szpyrkowicz L, Juzzolino C, Kaul SN. A comparative study on oxidation of disperse dyes by electrochemical process, ozone, hypochlorite and Fenton reagent. Water Res 2001; 35(9): 2129-36. doi: 10.1016/S0043-1354(00)00487-5.

2. Jaafarzadeh Haghighifard NA, Jorfi S, Ahmadi M, Mirali S, Kujlu R. Treatment of mature landfill leachate by chemical precipitation and Fenton advanced oxidation process. Environmental Health Engineering and Management Journal 2016; 3(1): 35-40.

3. Dindarloo K, Jamali HA, Lakbala P, Mahmoodi H, Kazemi F. Feasibility of electrochemical oxidation process for treatment of saline wastewater. Environmental Health Engineering and Management Journal 2015; 2(3): 129-34.

4. Jiang JQ, Panagoulopoulos A, Bauer M, Pearce P. The application of potassium ferrate for sewage treatment. J Environ Manag 2006; 79(2): 215-20. doi: 10.1016/j. jenvman.2005.06.009.

5. Jiang J. Research progress in the use of ferrate (VI) for the environmental remediation. J Hazard Mater 2007; 146(3): 617-23. doi: 10.1016/j.jhazmat.2007.04.075.

6. Jiang JQ, Wang S, Panagoulopoulos A. The role of potassium ferrate (VI) in the inactivation of Escherichia coli and in the reduction of COD for water remediation. Desalination 2007; 210(1): 266-73. doi: 10.1016/j.desal.2006.05.051.

7. Mohajeri S, Aziz HA, Isa MH, Zahed MA, Adlan MN. Statistical optimization of process parameters for landfill leachate treatment using electro-Fenton technique. J Hazard Mater 2010; 176(1-3): 749-58. doi: 10.1016/j. jhazmat.2009.11.099.

8. Montgomery Douglas C. Design and Analysis of Experiments. 8th ed. John Wiley \& Sons; 2008.

9. Ahmed AL, Ismail S, Bhatia S. Optimization of coagulationflocculation process for palm oil mill effluent using response surface methodology. J Environ Sci Tech 2005; 39(8): 2828-34. doi: 10.1021/es0498080.

10. APHA. Standard methods for the examination of water and wastewater 21 th ed Washington American Public Health Association; 2005.

11. Wu Y, Zhou S, Qin F, Ye X, Zheng K. Modeling physical and oxidative removal properties of Fenton process for treatment of landfill leachate using response surface methodology (RSM). J Hazard Mater 2010; 180(1-3): 45665. doi: 10.1016/j.jhazmat.2010.04.052.

12. Arslan-Alaton I, Akin A, Olmez-Hanci T. An optimization and modeling approach for $\mathrm{H} 2 \mathrm{O} 2 / \mathrm{UV}-\mathrm{C}$ oxidation of a commercial non-ionic textile surfactant using central composite design. J Chem Technol Biotechnol 2010; 85(4): 493-501. doi: 10.1002/jctb.2315.

13. Murmann RK, Robinson PR. Experiments utilizing $\mathrm{FeO}_{4}^{2-}$ for purifying water. Water Res 1974; 8(8): 543-7. doi: 10.1016/0043-1354(74)90062-1.

14. Bartzatt R, Cano M, Johnson L, Nagel D. Removal of toxic metals and nonmetals from contaminated water. J Toxicol Environ Health A 1992; 35(4): 205-10.

15. Ciabatti I, Tognotti F, Lombardi L. Treatment and reuse of dyeing effluents by potassium ferrate. Desalination 2010; 250(1): 222-8. doi: 10.1016/j.desal.2009.06.019.

16. Wang HL, Liu SQ, Zhang XY. Preparation and application of sustained release microcapsules of potassium ferrate (VI) for dinitro butyl phenol (DNBP) wastewater treatment. J Hazard Mater 2009; 169(1-3): 448-53. doi: 10.1016/j. jhazmat.2009.03.130.

17. Jiang JQ, Zhou Z, Patibandla S, Shu X. Pharmaceutical removal from wastewater by ferrate (VI) and preliminary effluent toxicity assessments by the zebrafish embryo model. Microchem J 2013; 110: 239-45. doi: 10.1016/j. microc.2013.04.002.

18. Barışçıa S, Ulu F, Sillanpää M, Dimoglo A. Evaluation of flurbiprofen removal from aqueous solution by electrosynthesized ferrate (VI) ion and electrocoagulation process. Chem Eng J 2015; 262: 1218-25. doi: 10.1016/j. cej.2014.10.083.

19. Han Q, Wang H, Dong W, Liu T, Yin Y, Fan H. Degradation of bisphenol A by ferrate (VI) oxidation: Kinetics, products and toxicity assessment. Chem Eng J 2015; 262: 34-40. doi: 10.1016/j.cej.2014.09.071.

20. Farooq S, Bari A. Tertiary treatment with ferrate and ozone. J Environ Eng 1986; 112(2): 301-10. doi: 10.1061/ (ASCE)0733-9372(1986)112:2(301). 